\title{
SUBSTITUIÇÃO DE ÁGUA FRESCA POR ÁGUA BRANCA EM SELAGEM DE BOMBAS DE VÁCUO
}

\author{
Luis Cesar Rodrigues ${ }^{1}$
}

Alexandre Augusto de Andrade ${ }^{2}$

\section{RESUMO}

As bombas de vácuo são equipamentos utilizados em máquinas de papel e são necessários para remoção de água. Para se ter uma boa formação da folha, é necessário ter um fluxo de massa na mesa plana com consistência em torno de 1\%, logo que se obtém uma boa formação da folha, a água começa a ser removida, primeiramente por gravidade, posteriormente por bombas de vácuo, prensas (feltros) e aplicação de vapor (troca térmica) chegando ao final com teor seco em torno de 92,5\%. Conforme a folha segue sentido máquina, a água fica cada vez mais difícil de ser removida e também mais cara é o processo de remoção, por isso é necessária uma boa eficiência das bombas de vácuo. A maioria das bombas de vácuo usa a água fresca como água de selagem, pois segundo os fabricantes, a temperatura não pode exceder $30^{\circ} \mathrm{C}$, por isso a água fresca acabou se tornando mais viável, pois possui uma temperatura em torno de $20^{\circ} \mathrm{C}$. Por outro lado, o uso de água fresca como água de selagem implica num impacto ambiental muito grande, devido ao alto consumo. O estudo realizado para minimizar os impactos ambientais se dá com a substituição de água fresca por água branca, já que têm características semelhantes.

PALAVRAS-CHAVE: Bomba de vácuo, Água fresca, Água branca.

\section{FRESH WATER REPLACEMENT FOR WHITE WATER IN VACUUM PUMPS SEALING}

\section{ABSTRACT}

\footnotetext{
1 Acadêmico do curso de Engenharia Química, Faculdade de Telêmaco Borba - FATEB, Telêmaco Borba - Paraná. E-mail: luiscesarrodrigues@bol.com.br

2 Orientador, Professor mestre do Curso de Engenharia Química, Faculdade de Telêmaco Borba-FATEB, Telêmaco Borba - Paraná. E-mail: aandrade@klabin.com.br
} 
The vacuum pumps are equipment used in paper machines and they are necessary for water removal. To get a good sheet generation, it's necessary to have a mass flow on the flat table with consistency around $1 \%$, right after getting a good sheet generation, the water begins to be removed, first by gravity, afterwards with vacuum pumps, presses (felts) and steam application (thermal exchange) getting to the end with a dry content around $92,5 \%$. As the sheet follows to the machine, the water gets increasingly difficult to be removed and more expensive the removal process is, therefore it is necessary a good efficiency of the vacuum pumps. Most of vacuum pumps use fresh water as sealing water, because according to the manufacturer, the temperature not exceeding $30^{\circ} \mathrm{C}$, that's why the fresh water eventually became more viable because it has a temperature around $20^{\circ} \mathrm{C}$.. On the other hand, the fresh water, use as sealing water implies on a too big environmental impact, due to high consumption. The study realized to minimize the environmental impacts occurs by the fresh water to the white water substitution, as it has similar characteristics.

KEY-WORDS: Vacuum pumps, fresh water, white water.

\section{REEMPLAZO DE AGUA DULCE DE AGUA BLANCA EN BOMBAS DE VACÍO DE SELLADO}

Las bombas de vacío son dispositivos utilizados en las máquinas de papel y son necesarios para eliminar el agua. Para obtener una buena formación de la hoja, debe tener un flujo de masa en la tabla plana con consistencia alrededor del 1\%, por lo que obtener una buena formación de la hoja, el agua comienza a ser eliminado, primero por la gravedad, entonces por bombas de vacío, prensas (fieltro) y vapor (transferencia de calor) llega a su fin con la sequedad alrededor de 92,5\%. Como la hoja sigue la dirección de la máquina, el agua se vuelve cada vez más difíciles de eliminar y también más caro es el proceso de eliminación, por lo que se requiere una buena eficiencia de la bomba de vacío. La mayoría de las bombas de vacío utilizan agua dulce como agua de sellado, porque de acuerdo con el fabricante, la temperatura no debe exceder los $30^{\circ} \mathrm{C}$, por lo que el agua dulce resultó ser más viable porque tiene una temperatura alrededor de $20^{\circ} \mathrm{C}$. Por otro lado, el uso de agua dulce como agua de sellado implica un gran impacto ambiental debido al alto consumo. El estudio para reducir al mínimo los impactos ambientales se da mediante la sustitución de agua dulce con agua blanca, ya que tienen características similares.

PALABRAS-CLAVE: Bomba de vacío, agua dulce, agua blanca.

\section{INTRODUÇÃO}

O meio ambiente vem sofrendo mudanças significativas no decorrer dos anos, os rios têm sentido esses impactos ambientais com o aumento da poluição e redução de seus leitos, por isso, o uso responsável da água vem se fortalecendo na sociedade. 
O consumo sustentável na indústria, envolve a escolha de produtos e equipamentos que utilizam menos recursos naturais em sua produção, sem haver perdas de eficiência. Algumas indústrias de papel possuem essa responsabilidade ambiental e sempre tentam usar a água de forma racional, reciclando a água do processo e tentando reduzir a demanda de água fresca.

Água fresca é um termo usado nas indústrias de celulose e papel para a água tratada (não potável), onde sua temperatura é em torno de $20^{\circ} \mathrm{C}$, essa água é usada principalmente em equipamentos como trocadores de calor, condensadores, chuveiros, etc.

Água branca é um resíduo gerado na seção de formação (drenagem) e desaguamento na seção das prensas, essa água contém fibras de celulose, é enviada a um separador tipo filtro de discos, onde as fibras são separadas do filtrado, sendo ambas, usadas em circuito fechado. $O$ excesso de água branca é é usada em chuveiros e controle de consistência e o restante é enviado ao ETE, já que a máquina de papel não consegue absorver toda demanda.

O papel kraftliner, ou papel marrom, é produzido basicamente com água, fibras de celulose e aditivos químicos. A celulose é a principal matéria prima, podendo ser fibras virgens de pinus ou eucalipto, recicladas ou, um mix.

Este trabalho foi construído levando em consideração, dados e equipamentos da máquina de papel kraftliner $n^{\circ} 06$ (MP6) da unidade Klabin Monte Alegre, localizada em Telêmaco Borba, estado do Paraná.

A MP6 produz papel kraftliner com gramaturas que variam de $90 \mathrm{~g} / \mathrm{m}^{2}$ à $135 \mathrm{~g} / \mathrm{m}^{2}$ e tem como destino a conversão em caixas de papelão, lixas e sacos, sua produção pode chegar à $29 \mathrm{t} / \mathrm{h}$.

As máquinas de papel kraftliner são divididas basicamente em três seções: 


\subsection{Formação}

Na seção de formação da MP6, a folha de papel começa a ser formada através da deposição de fibras de uma suspensão aquosa sobre a tela da máquina. Esta tela desliza sobre uma mesa plana onde existem caixas de vácuo (figura 1), que removem a água do material fibroso de maneira gradativa.

Figura 1 - Caixas de Hidofoils da MP 6, geração de vácuo por gravidade.

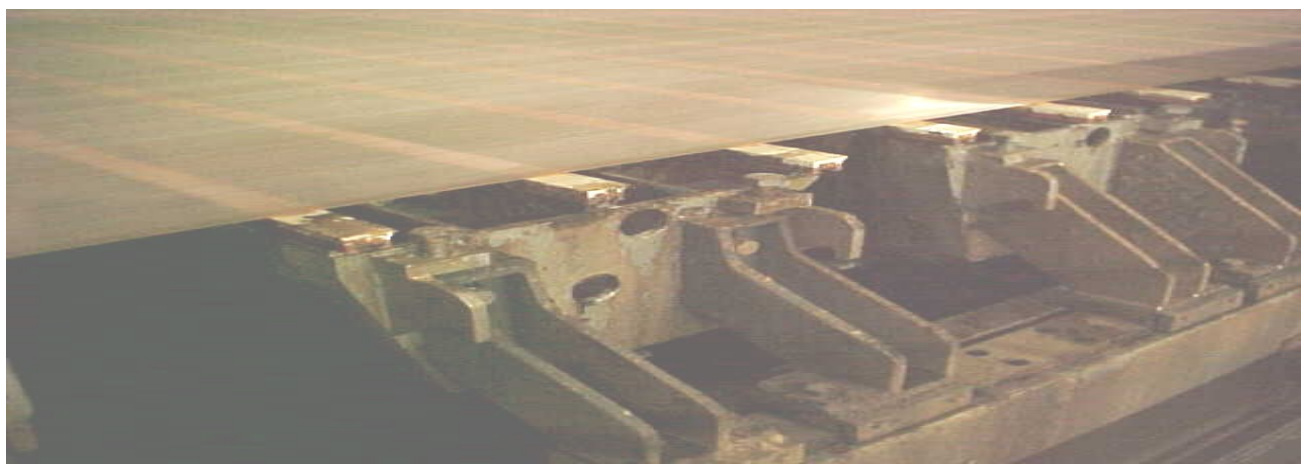

Fonte: OPERAÇÃO MP 6, 2014

Figura 2 - Caixa de sucção da MP 6, através de bombas de vácuo.

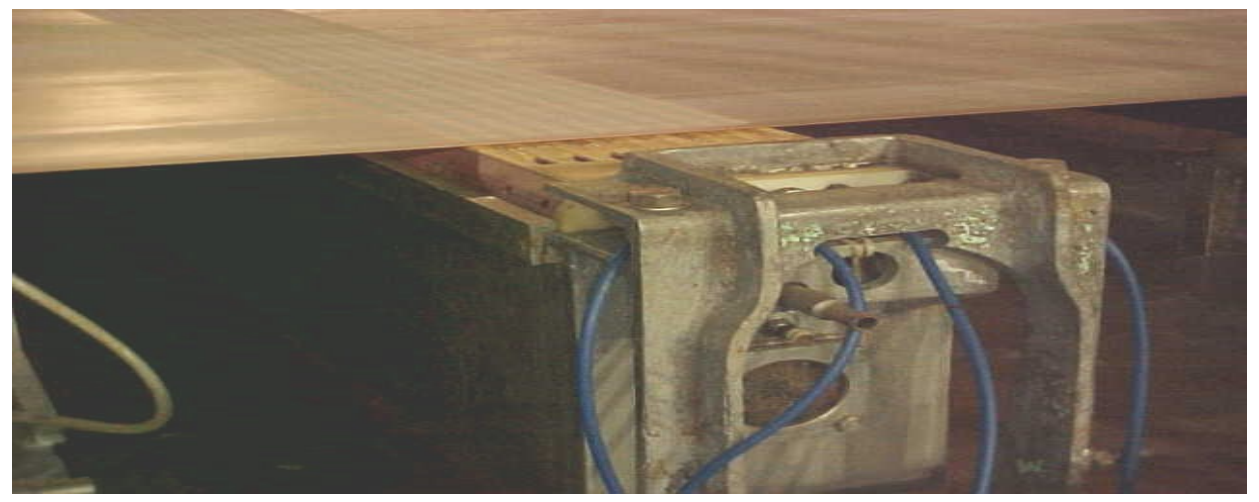

Fonte: OPERAÇÃO MP6, 2014

\subsection{Prensas}


A função principal das prensas é a remoção da máxima quantidade de água da folha de papel antes que esta, entre na seção de secagem da máquina e, também, alisar a folha de modo a eliminar as marcas deixadas pela tela da mesa plana, influenciando na densidade da folha. Na MP6 existem três prensas, revestidas com feltros, com pressões nos nip's que variam entre 100$135 \mathrm{Kg} / \mathrm{cm}^{2}$. A água é removida do papel, fazendo com que fique alojadas no feltro, conforme o feltro faz o circuito, passa por uma sucção (figura 3) fazendo com que a água seja removida, chegando novamente ao nip com condições de remover água do papel novamente.

Figura 3 - Caixas de sucção das prensas

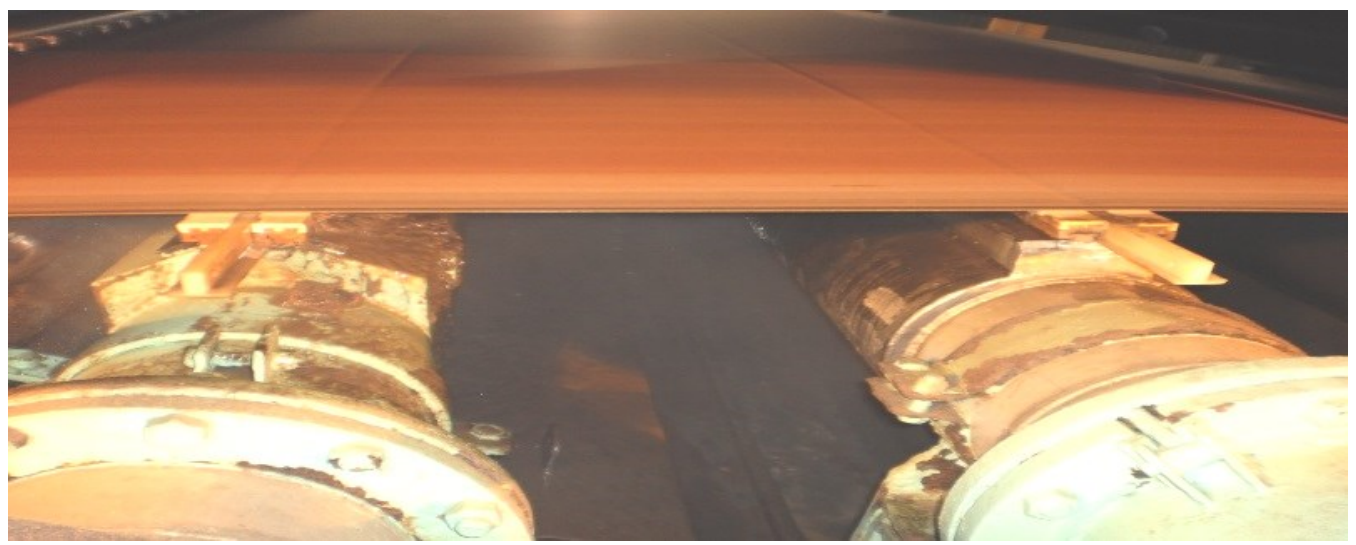

Fonte: OPERAÇÃO MP6, 2014

\subsection{Secagem}

A seção de secagem da MP6 é composta por 54 cilindros secadores, no qual são divididos em quatro grupos secadores, sendo que cada grupo recebe vapor com pressões diferentes, respeitando uma curva de secagem, crescendo gradativamente. Nessa seção, a água é removida através de troca térmica, onde a folha é forçada a passar entre o cilindro secador e uma tela secadora. A temperatura do vapor é em torno de $160^{\circ} \mathrm{C}$ e a pressão de entrada de vapor é 4,0 bar. 
Gráfico 1 - Comparativo de umidade x seções da MP 6.

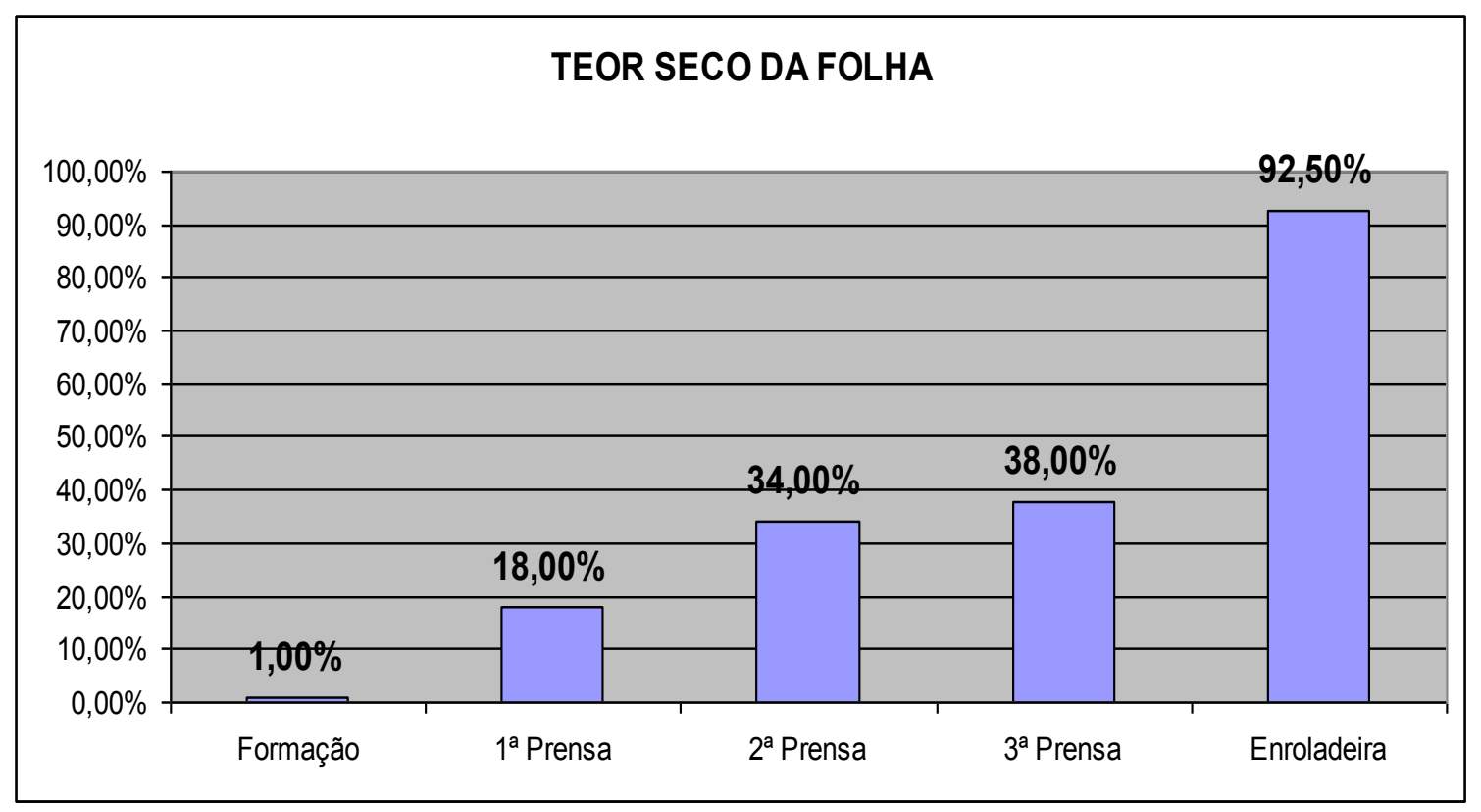

Fonte: LABORATÓRIO DE TESTES FÍSICOS DA KLABIN MONTE ALEGRE, 2014.

\title{
2.Bombas de Vácuo (ou bombas de anel líquido)
}

São as mais usadas e preferidas. Segundo a Nash do Brasil, fabricante de bombas. (2014), o funcionamento de uma bomba de vácuo consiste em:

\begin{abstract}
Um rotor (1), em equilíbrio dinâmico, girando livremente sem qualquer contato metálico em uma carcaça circular (3) que contém água de selagem (4). Este rotor (1) é uma peça fundida circular que compreende uma série de palhetas que saem de um cubo cilíndrico ôco, através do qual é prensado o eixo. Estas palhetas são fechadas lateralmente, formando uma série de câmaras ou compartimentos. Observe-se que a curvatura das palhetas está orientada no sentido de rotação. Partindo do ponto "A", os compartimentos do rotor estão cheios de água. Esta água (4) que preenche completamente a câmara do rotor em "A", retrocede à medida que o rotor avança, até que em (5) a câmara do rotor se esvazia. A forma convergente da carcaça força a água a voltar para o interior da câmara do rotor, de modo que, em (6) está cheia de novo. Este ciclo se repete em cada revolução. Quando a água é forçada a sair do compartilhamento do rotor (7), é substituída por ar que entra pela abertura de admissão na peça cônica (2), que por sua vez está conectada com a entrada da bomba. Quando o rotor tiver girado de $360^{\circ}$, a água é forçada pela carcaça a voltar para o interior da câmara do rotor, e o ar que havia preenchido este compartimento, é obrigado a sair através das aberturas de descarga existentes na caixa cônica (2), para a saída da bomba. (NASH DO BRASI, 2014, p.8).
\end{abstract}


Figura 4 - Esquema demonstrando o funcionamento de uma bomba de vácuo.

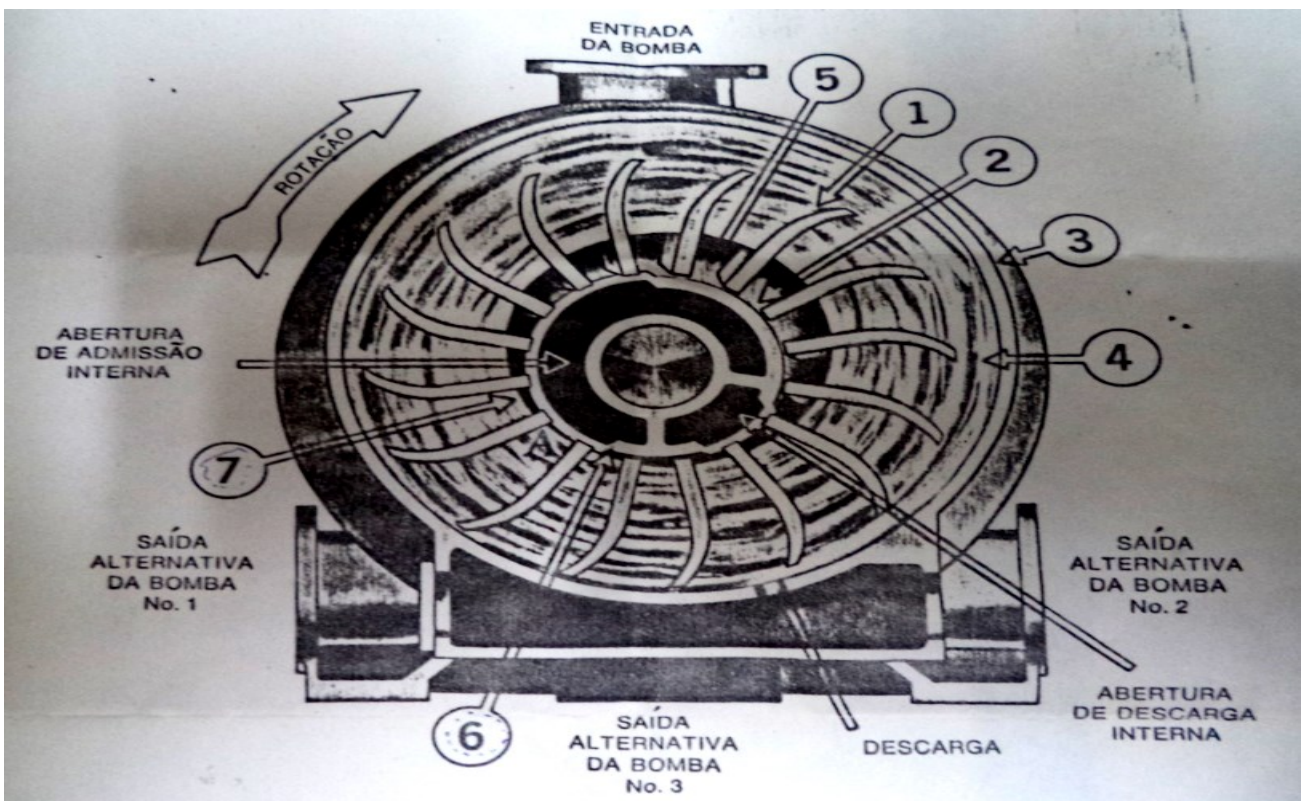

Fonte:NASH DO BRASIL, 2014.

\title{
2.1 Água de Selagem
}

Segundo Filho, (2013), a água de selagem é utilizada para,

\begin{abstract}
vedar as aberturas entre o rotor e o cabeçote de comando, além de remover as fibras arrastadas na aspiração. Para bom funcionamento da bomba é necessária a boa manutenção das gaxetas do eixo. $O$ circuito do sistema de água de selagem da bomba pode ser aberto, fechado (com bombeamento, filtragem, controle químico, refrigeração e reposição) ou em cascata (indo das bombas de alto vácuo para as bombas aplicadas em baixo vácuo). (REVISTA O PAPEL, 2013, p.58).
\end{abstract}

Segundo a Nash do Brasil (2014), esta água deve ser fresca, com pH neutro, sem partículas abrasivas, com temperatura não excedendo os $30^{\circ} \mathrm{C}$, pois quanto maior este valor maior será a pressão que os vapores exercerão na câmara, diminuindo o espaço destinado ao ar (NASH DO BRASIL BOMBAS, 2014).

Na MP-6 existem 12 bombas de vácuo (figura 5), sendo $50 \%$ da marca Voith e $50 \%$ da marca Nash, projetadas em cinco pontos na zona de formação e em oito pontos na zona de prensas. 
Figura 5 - Bombas de vácuo da MP 6.

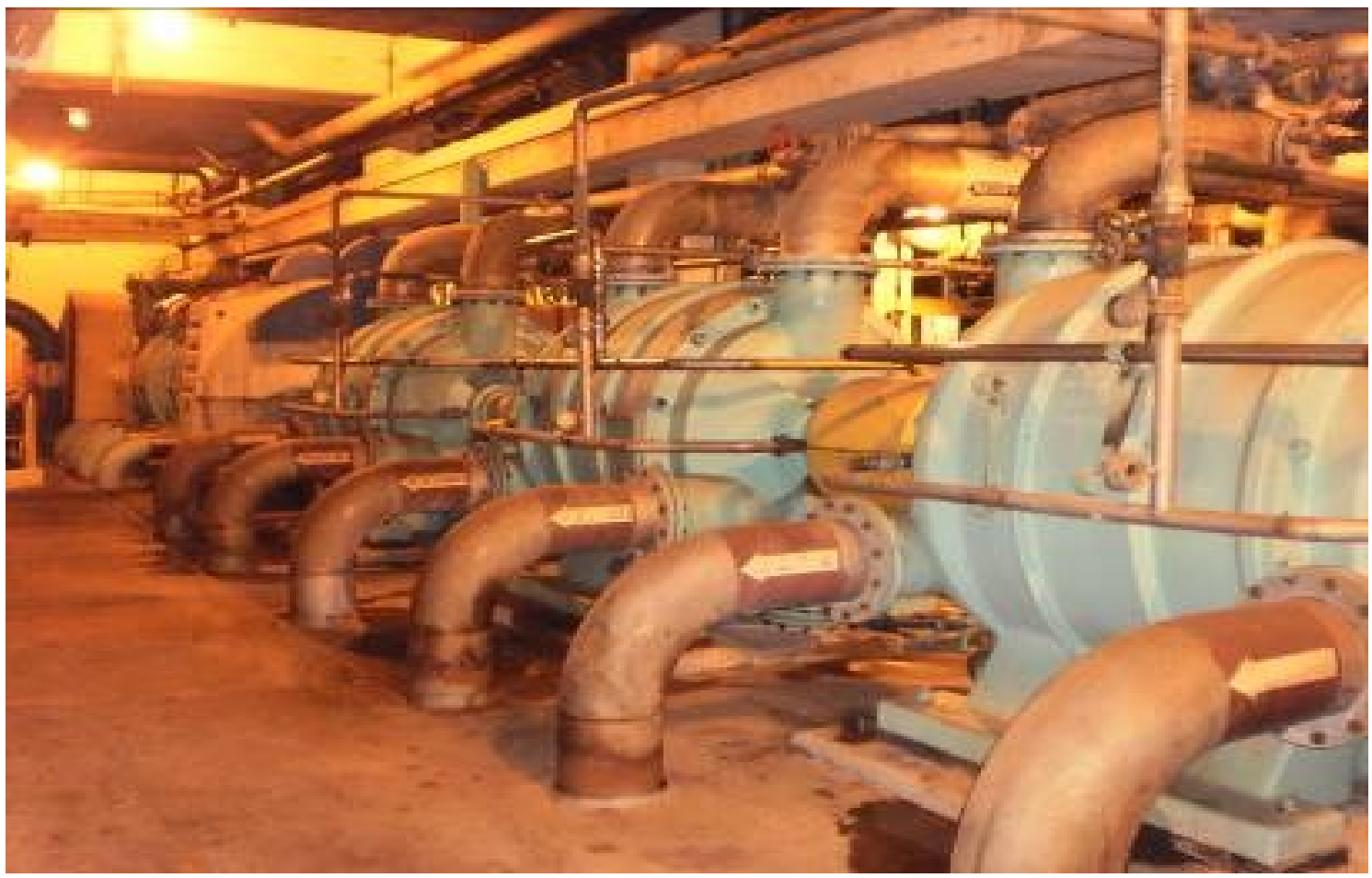

Fonte: OPERAÇÃO MP6, 2014.

\section{DESENVOLVIMENTO}

Primeiramente, foram levantados dados de consumo de água fresca, onde constatou-se que, das quatro principais máquinas de papel atualmente em operação nesta unidade, a MP6 tinha o maior consumo específico (gráfico 2). 


\section{RESULTADOS E DISCUSSÃO}

Após conhecer os pontos consumidores e suas vazões de água fresca na MP6, a água fresca para selagem das bombas de vácuo foi substituída por água branca, já que a água branca possui características parecidas com a água clara, as fibras presentes na água branca são hidrofílicas, ou seja, possuem afinidade com a água e irão interagir com a mesma água branca removida dentro da bomba de vácuo.

O maior desafio foi não perder eficiência nas bombas de vácuo, já que a água fresca tem temperatura em torno de $21^{\circ} \mathrm{C}$ (figura 6) e é ideal para serem usadas em bombas de vácuo (NASH DO BRASIL, 2014). Uma perda de eficiência das bombas de vácuo, acarreta num papel mais úmido na seção de secagem, consumindo maior quantidade de vapor, se tornando inviável, já que o vapor é o componente mais caro no processo de fabricação de papel.

Para baixar a temperatura da água branca, que é em torno de $49^{\circ} \mathrm{C}$ (figura 6), foi instalada uma Torre de Resfriamento modelo "Alpina" (figura 7), onde se conseguiu uma temperatura inicial em torno de $28,5^{\circ} \mathrm{C}$.

Figura 6 - Fotos mostrando as temperaturas de água branca e água fresca.

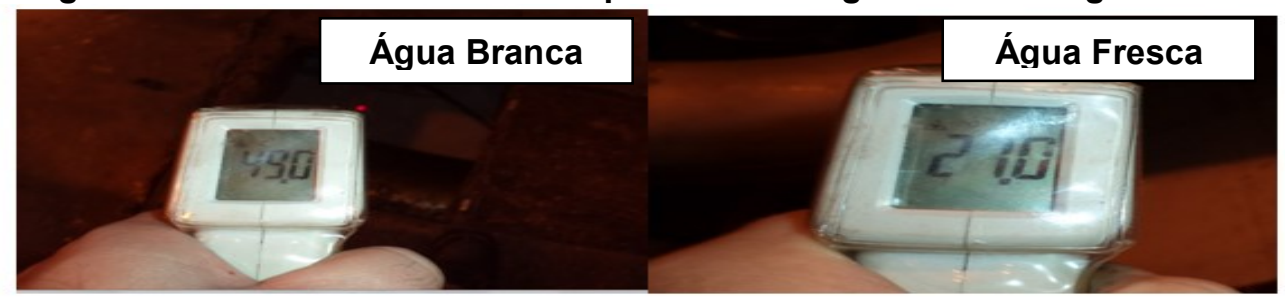

Fonte: OPERAÇÃO MP6, 2014.

Figura 7 - Foto da torre de resfriamento modelo alpina da MP6.

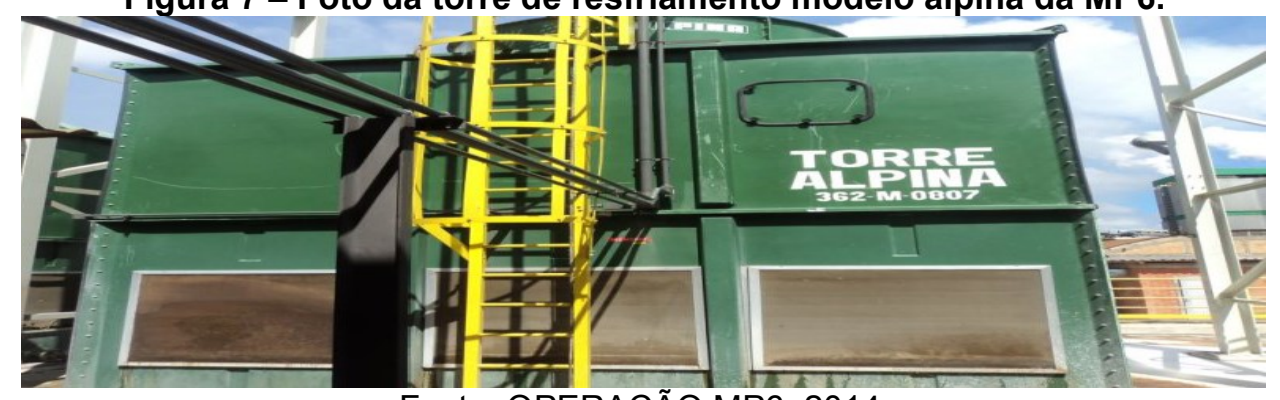

Fonte: OPERAÇÃO MP6, 2014. 


\subsection{Dificuldades}

À medida que o tempo foi passando, a temperatura de retorno da torre alpina ia ultrapassando os $30^{\circ} \mathrm{C}$, gerando um problema de perda de eficiência nas bombas de vácuo (NASH DO BRASIL, 2014). Foi feito uma análise e constatado que no topo na torre alpina, o sistema de exaustão era por correias e, devido a umidade, essas correias afrouxavam ou caíam. Para resolver esse problema, foi substituído o modelo de correias por redutores. Com isso, conseguiu-se um maior rendimento da torre de resfriamento, com ganhos de temperatura, fazendo com que a água branca tivesse uma temperatura inferior à $30^{\circ} \mathrm{C}$.

Outro problema eram as incrustações (figura 8) geradas na torre alpina devido as impurezas da água branca que acabavam se transformando em borras, afetando as chicanas, sendo arrastadas para as bombas de vácuo, ocasionando perda de eficiência devido a entupimentos e perdas de pressão. Esse problema foi resolvido com a criação de um procedimento de limpeza em toda parada de máquina, usando água fresca ou morna na circulação das linhas ou até mesmo uma limpeza química, sendo drenado antes das bombas de vácuo, evitando assim, que impurezas acabem sendo arrastadas para dentro das mesmas. A geração de espuma era outra dificuldade, que conseguiu-se resolver, injetando água fresca num ponto antes da torre alpina de tempos em tempos que acabavam eliminando toda a espuma do processo.

A geração de espuma se dá por alguns pontos das zonas de vácuo não haver separadores de vácuo, equipamento que serve para separar o líquido do gás através de gravidade, fazendo com que o líquido siga para um tanque, onde é posteriormente bombeado para o canal das bombas de vácuo e o gás sendo liberado para a atmosfera. Este gás (ar + algumas impurezas) acabam sendo arrastadas para a torre alpina ocasionando geração de espumas. Uma solução definitiva seria a implantação de novos separados de vácuo, mas como viabiliza um alto custo de investimento, surgiu a idéia de gastar aproximadamente $200 \mathrm{~m}^{3} /$ semana de água fresca para realizar essa limpeza no 
circuito. Limpeza que pode ser feita mesmo com a máquina em operação, não afetando o processo nem a eficiência das bombas e vácuo.

Figura 8- Fotos das chicanas da torre alpina comparando as incrustações.
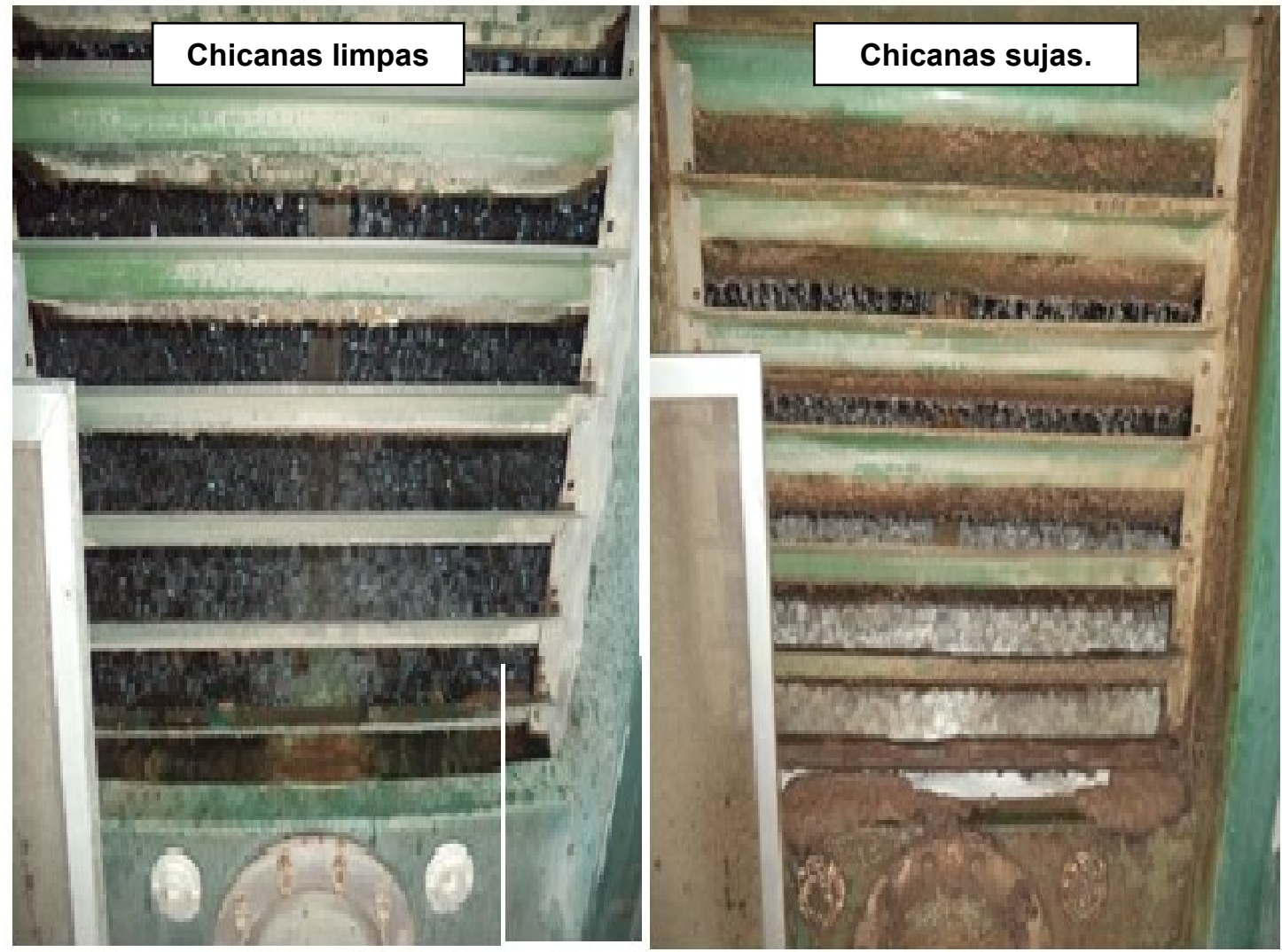

Fonte: OPERAÇÃO MP6, 2014.

\subsection{Monitoramento}

Foi realizado um monitoramento frequente nas prensas (tabela 1) e na seção de formação (gráfico 4), para analisar a eficiência de drenagem. Trabalho feito por fornecedores parceiros de feltros e telas formadoras, realizados com equipamentos que medem a quantidade de água antes e, após a drenagem, o que comprovou que a eficiência das bombas de vácuo não foi alterada. 
Tabela 1 - Relatório de drenagem da $1^{a}$ prensa da MP 6 mostrando que não houve perdas de eficiência nas bombas de vácuo.

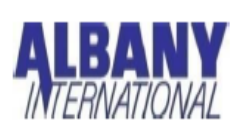

RESUMO DA $1^{\text {a } P R E N S A ~}$

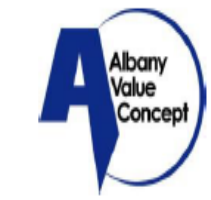

\begin{tabular}{|c|c|c|c|c|c|c|c|c|c|c|c|}
\hline Data do levantamento & & $02107 / 14$ & 08/05/14 & $14 / 02 / 14$ & 04/02/14 & $16 / 01 / 14$ & $04 / 09 / 13$ & $15 / 08 / 13$ & 09/07/13 & $11 / 06 / 13$ & $20 / 02 / 13$ \\
\hline Tipo de Papel & & 4ᄂ & LLO90 & LLB 125 & LLO90 & LLB 100 & LLB 110 & & LLp 90 & SLF 80 & LLO9O \\
\hline Gramatura & $\mathrm{g} / \mathrm{m}^{2}$ & 1e. & 90,0 & 125,0 & 90,0 & 100,0 & 110,0 & & 80,0 & 80,0 & 90,0 \\
\hline Velocidade prensas & $\mathrm{m} / \mathrm{min}$ & 592 & 568 & 426 & 622 & 594 & 617 & 523 & 626 & 610 & 601 \\
\hline Vapor Especifico & th & 2,08 & 2,41 & 2,20 & 2,15 & 2,23 & 2,09 & 2,22 & 2,18 & 2,48 & 2,50 \\
\hline \multicolumn{12}{|l|}{ FELTROS } \\
\hline Data Instalação &.- & $22105 / 14$ & $12102 / 14$ & $12 / 02 / 14$ & $06 / 11 / 13$ & $06 / 11 / 13$ & $07108 / 13$ & $07108 / 13$ & $25 / 05 / 13$ & $25 / 05 / 13$ & $12 / 12 / 12$ \\
\hline Dias em Máquina & $d$ & 41 & 85 & 2 & 90 & 71 & 28 & 8 & 45 & 17 & 70 \\
\hline Fornecedor & - & Voith & Albany & Albany & Voith & Voith & Albany & Albany & Albany & Albany & Heimbach \\
\hline Número & - & 10869458 & $30321977-10$ & $30321977-10$ & 10813343 & 10813343 & $30343446-10$ & $30343446-10$ & $30311671-10$ & $30311671-10$ & 511836 \\
\hline Estilo & -- & Nulffex AS2 & SeamOynatex II & Seamoynatex II & Mutffex AS2 & Musflex AS2 & SeamDyntex \| & SesmDynatex II & SesmDynatex II & SeamDynatex II & Atroplan \\
\hline Gramatura & $\mathrm{g} / \mathrm{m}^{2}$ & 1437 & 1439 & 1439 & 1485 & 1485 & 1460 & 1460 & 1447 & 1447 & 1640 \\
\hline Permeabilidade estática & $\mathrm{cfm}$ & 103 & 114 & 114 & 0 & 0 & 111 & 111 & 112 & 112 & 65 \\
\hline Massa de água antes do nip & $\mathrm{g} / \mathrm{m}^{2}$ & 662 & 707 & 636 & 740 & 794 & 579 & 549 & 608 & 623 & 711 \\
\hline Relação AlF & $g / g$ & 0,46 & 0,49 & 0,44 & 0,50 & 0,53 & 0,40 & 0,38 & 0,42 & 0,43 & 0,43 \\
\hline Remoção de água & $\mathrm{g} / \mathrm{m}^{2}$ & 153 & 109 & 151 & 119 & 139 & 120 & 95 & 86 & 70 & 124 \\
\hline Volume ativo & $\%$ & 420 & 32,1 & 44,4 & 39,1 & 42,5 & 35,8 & 40,2 & 33,9 & 38,7 & 36,3 \\
\hline Perm. Dinâmica & $\mathrm{m}^{3} / \mathrm{m}^{2} / \mathrm{min}$ & 165 & 168 & 178 & 184 & 180 & 191 & 260 & 180 & 202 & 222 \\
\hline Tempo da última $L . Q$. & dias & - & - & - & - & 1 & Continuo & 1 & - & - & - \\
\hline \multicolumn{12}{|l|}{ PRENSAS } \\
\hline Condições do Nip & -- & saturado no LA & saturado & seco & $\sec 0$ & $\operatorname{seco}$ & saturado & $\sec 0$ & saturado & saturado & saturado \\
\hline Pressão Manométrica & bar & 110,95 & 110,15 & 109,6 & 111,15 & 116 & 105,75 & 101,95 & 96,95 & 96,05 & 101,9 \\
\hline Pressão Linear & $\mathrm{kN} / \mathrm{m}$ & 115 & 114 & 113 & 115 & 122 & 108 & 103 & 96 & 95 & 103 \\
\hline Int. Prensagem & $\mathrm{kPas}$ & 11,67 & 12,04 & 15,95 & 11,13 & 12,33 & 10,50 & 11,78 & 9,18 & 9,30 & 10,25 \\
\hline \multicolumn{12}{|l|}{ CONDICIONAMENTO } \\
\hline Dif. Vácuo & mca & 3,8 & 4,2 & 3,9 & 3,9 & 3,8 & 4,1 & 3,3 & 3,8 & 3,9 & 2,6 \\
\hline Velocidade ar & $\mathrm{m} / \mathrm{s}$ & 5,3 & 5,2 & 5,8 & 5,9 & 5,6 & 6,4 & 7,5 & 5,2 & 6,4 & 5,9 \\
\hline Dif. Vácuo & mca & 3,8 & 4,2 & 3,9 & 3,9 & 3,8 & 4,1 & 3,3 & 3,8 & 3,9 & 2,6 \\
\hline Velocidade ar & $\mathrm{m} / \mathrm{s}$ & 5,1 & 5,7 & 5,8 & 6,0 & 5,8 & 5,5 & 7,8 & 5,8 & 6,6 & 5,2 \\
\hline \multicolumn{12}{|l|}{ RESUMO CONDICIONAMENTO } \\
\hline Tempo de permanência & ms & 3,85 & 4,01 & 5,35 & 3,67 & 3,84 & 3,70 & 4,36 & 3,64 & 3,74 & 3,79 \\
\hline Fluxo especifico médio & $\mathrm{L} / \mathrm{cm}^{2} / \mathrm{min}$ & 70,2 & 78,0 & 77,1 & 78,5 & 74,8 & 81,4 & 85,5 & 73,0 & 83,7 & 59,8 \\
\hline Vazão total de ar & $\mathrm{m}^{3} / \mathrm{min}$ & 190,7 & 211,8 & 209,5 & 213,3 & 203,3 & 221,1 & 232,2 & 198,2 & 227,3 & 162,4 \\
\hline
\end{tabular}

Fonte: ALBANY INTERNATIONAL, 2014. 
Volume 10, Número 1, 2014

Aplicação de Novas Tecnologias Sustentáveis

Gráfico 4 - Histórico das medições de drenagem.

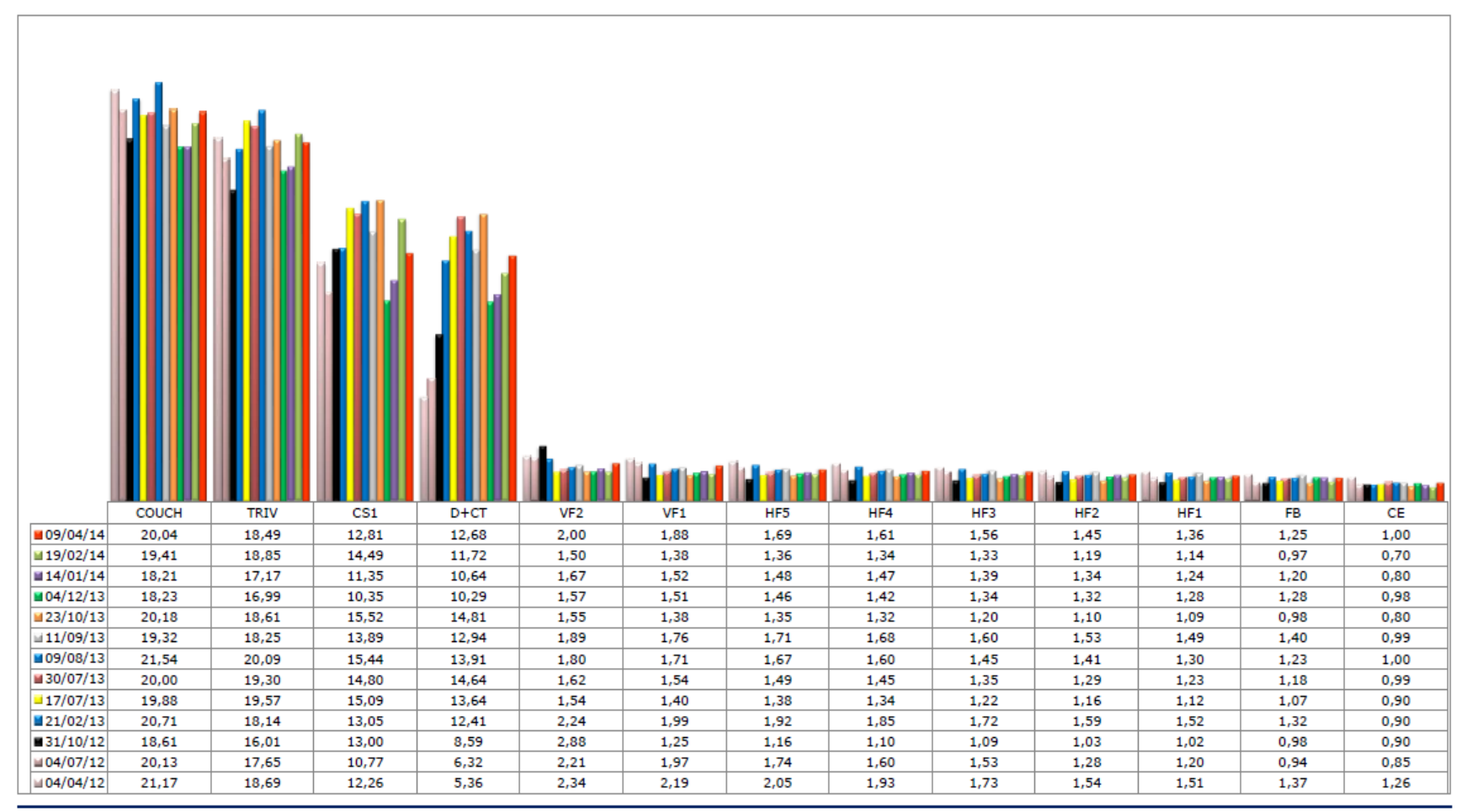

Fonte: ANDRITZ PULP \& PAPER, 2014.

\subsection{Consumo de Vapor}

Outra forma de provar que a eficiência das bombas de vácuo se manteve estável, é o consumo específico de vapor, que se manteve na média, comparada antes e, após a substituição do tipo de água de selagem (gráfico 5 ).

Segundo o Técnico da DAG QUÍMICA especialista em condicionamento de feltros e telas (2014), o consumo específico de vapor ideal no Brasil, para fabricação de papel kraft é, em torno de 2,10 à 2,15 . (DAG QUÍMICA, 2014.).

Para os dados do gráfico 5 , foram coletados valores de consumo específico de vapor para produção acima de $25 \mathrm{t} / \mathrm{h}$, pois produção acima desse valor, não há perda de vapor para atmosfera, não havendo um falso valor de consumo específico de vapor. Outras variáveis estipuladas foram, $\mathrm{pH}=6,4$, já 
que $\mathrm{opH}$ influencia diretamente na drenagem e consequentemente no consumo de vapor. Também ${ }^{\circ} \mathrm{SR}=30$ (grau shopper) que mede o grau de refinação da polpa, outra variável que influencia diretamente na drenagem e também no consumo de vapor.

Gráfico 5 - Consumo específico de vapor da MP 6 nos anos de 2013 e 2014.

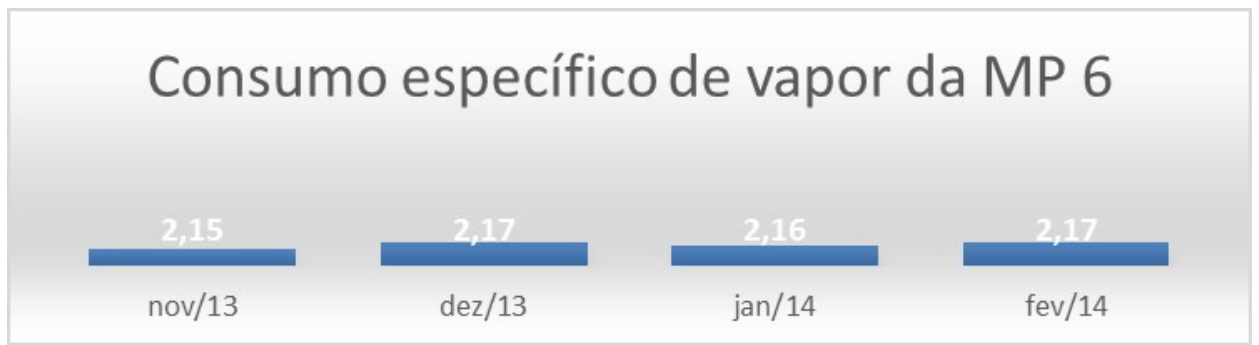

Fonte: BOLETIM TÉCNICO MP 6, 2014.

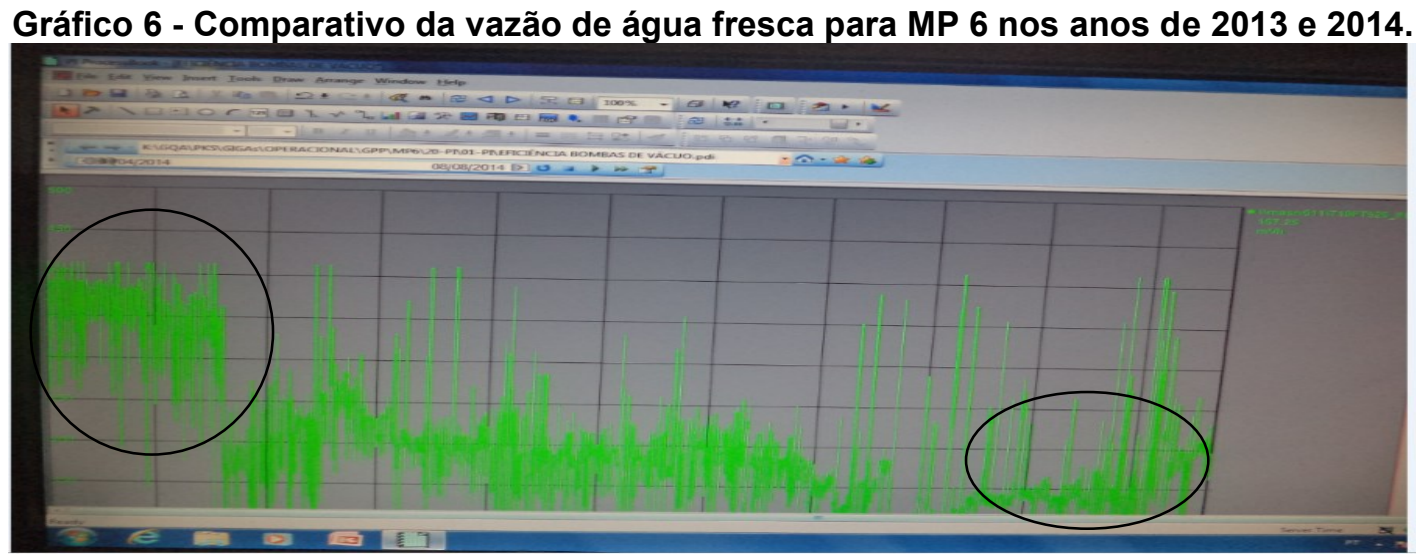

Fonte: Fonte: PI PROCESS BOOK KLABIN MONTE ALEGRE, 2014.

Gráfico 7 - Comparativo do consumo específico de água fresca

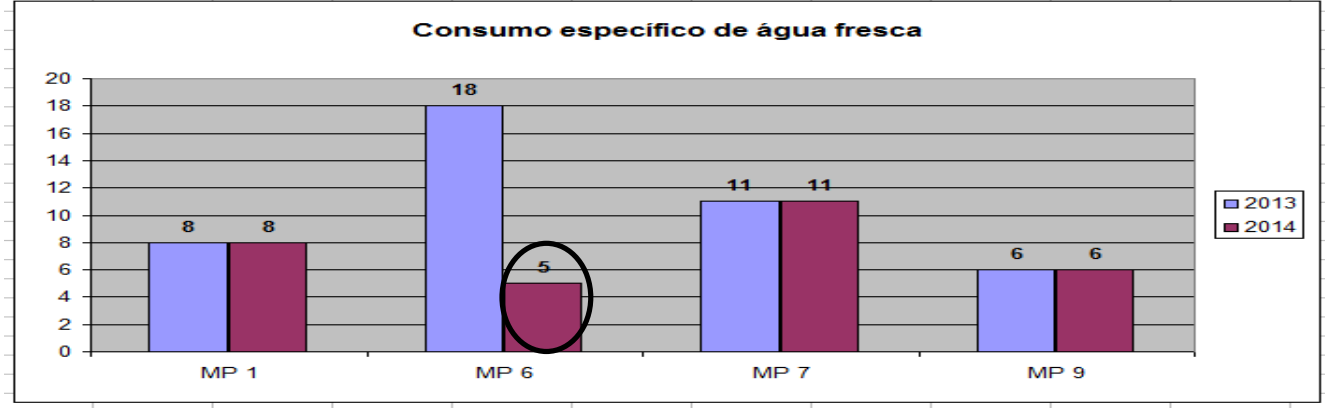

Fonte: PI PROCESS BOOK KLABIN MONTE ALEGRE, 2014. 


\section{CONCLUSÃO}

A partir dos resultados obtidos, permitem concluir que, é possível e viável, a substituição de água fresca por água branca na selagem de bombas de vácuo. Apesar das dificuldades encontradas em adequar o processo, equipamentos e pessoas, a substituição é benéfica ao meio ambiente e, à planta da unidade Monte Alegre da Klabin, onde conseguiu reduzir a demanda da ETA e a vazão de efluentes.

A MP6 tinha o pior desempenho quando comparada às outras máquinas da mesma unidade, no consumo de água, passando agora, para o primeiro lugar do ranking (gráfico 7 ), se igualando à máquinas de papel mais modernas.

Mesmo com o acréscimo da temperatura da água de selagem, não houve perda de eficiência das bombas de vácuo e, por isso, não houve aumento no consumo de vapor. A substituição de água fresca por água branca na selagem de bombas de vácuo impactou, numa economia de $152 \mathrm{~m}^{3} / \mathrm{h}$ no consumo de água da planta, valor esse, que resulta em torno de $109.000 \mathrm{~m}^{3} \mathrm{de}$ água por mês, ou seja, uma redução significativa de 180\% (gráfico 6).

\section{REFERÊNCIAS}

Celso-Foelkel. Fechamento de circuitos de águas em máquinas de papel. Disponível em:

http://www.celso-

foelkel.com.br/artigos/outros/94 Fechamento\%20circuitos\%20Maquina\%20Papel.pdf Acesso em: 02 set. 2014.

FILHO, Cesar de Araújo Góss. Sistema de vácuo na seção de formação da folha de papel. Revista o Papel, São Paulo: Julho, 2013. 57 p.

FRANÇA, Júnia Lessa et al. Manual para normalização de publicações tecnico-cientificas. 6. ed. rev. e ampl. Belo Horizonte: UFMG, 2003. 230 p.

JUNIOR, Volni Nunes de Moraes. Condicionamento de máquinas de papel kraft. 26. ed. rev. momento técnico Albany International, Indaial, SC: Setembro, 2011. 3 p.

UFSM. Ecoeficiência na gestão da perda de fibras de celulose e do refugo gerado na fabricação do papel. Disponível em: http://coral.ufsm.br/dcfl/seriestecnicas/fibras refugos.pdf Acesso em: 02 set. 2014. 